\title{
Recommendations towards the Tobacco Endgame from international workshop on smoking cessation interventions
}

\section{Luke Clancy ${ }^{1}$, Josep M. Suelves², Hans Gilljam³, Göran Boethius4, Iréne Nilsson-Carlsson ${ }^{5}$, Mette Gry Münchow ${ }^{6}$, Anne Sode Grønbæk7, Hanne Tønnesen ${ }^{7}$}

On December 14 and 15, 2016, an international multidisciplenary panel met in Copenhagen for an international workshop on the process towards the Tobacco Endgame.

\section{About the Workshop}

The workshop was held at Clinical Health Promotion Centre, WHO-CC, Frederiksberg Hospital, Denmark.

Affiliation of workshop participants:

${ }^{1}$ TobaccoFree Institute, Focas Institute DIT, Dublin, Ireland

${ }^{2}$ Servei de Prevenció I Control del Tabaquisme,

Catalonia, Spain

${ }^{3}$ Karolinska Institute, Sweden

4Tobaksfakta, Sweden

5The National Board of

Health and Welfare, Sweden

${ }^{6}$ The Danish Cancer Society,

Denmark

${ }^{7}$ The Danish Smoking Cessation Database, Clinical

Health Promotion Centre,

WHO-CC, Denmark

Contact:

Hanne Tønnesen

Hanne.tonnesen@regionh.dk

\section{The Tobacco Endgame}

The WHO Framework Convention for Tobacco Control (WHO FCTC) is an evidence-based treaty which reaffirms the right of all people to the highest standard of health ${ }^{1}$ through both preventing new smokers to start and supporting current smokers to quit. The WHO FCTC has been ratified by 180 countries including Sweden, Ireland, Spain and Denmark ${ }^{2}$. The long-term goal of the treaty is to eliminate smoking and has inspired several countries and regions to formulate a strategy to phase out smoking by a specific year. For the same reason the process has earned the name the Tobacco Endgame (TE).

\section{The scope and purpose of the work-} shop

The focus of the workshop was on supporting current smokers to quit through the best smoking cessation interventions (SCI) - with specific attention to vulnerable groups. The scope and purpose was a comparison of SCI on a national and local level to identify how countries and regions can collaborate internationally to ensure the quality of SCI and moving forward towards TE.

Recommendations - Tobacco Endgame requires effective SCI

No TE if smokers do not quit smoking Databases are essential for measuring the effect of SCI i.e. quit rates.

\section{Follow up of SCI}

This is crucial and shows that compliance is the main factor for success.
Follow-up of unsuccessful quitting attempts can also be used as a recruitment tool for further efforts.

\section{International standards}

Monitoring using international standards makes comparisons between countries and regions doable.

\section{Fast feedback}

Giving quick meaningful responses to health professionals on the effect of their SCI is more pro-active than just controlling who is doing what. It also increases the will to register data and to faster improvement of SCI.

\section{Vulnerable groups}

It is crucial to include groups of smokers at very high risk and/or frequency:

- Pregnant women

- Surgical patients

- Mentally ill patients. Offering them SCI (often for the first time), protecting them and keeping in mind that also most mental patients want to quit.

- Other vulnerable and disadvantaged groups.

Establish a platform for counsellors It is necessary to learn from each other. Counsellors are often working in very small groups or alone.

\section{References}

(1) WHO Framework Convention on Tobacco Control (2005). World Health Organisation, Geneva. http://apps.who.int/iris/bitstream/10665/42811/1/9241591013.pdf?ua=1 (2) WHO Framework Convention on Tobacco Control (2003). World Health Organisation, Geneva. https://treaties.un.org/pages/ViewDetails.aspx?src $=$ TREATY\&mtdsg no=IX-4\&chapter $=9 \&$ clang $=$ en 